Int. J. Electrochem. Sci., 11 (2016) 9481 - 9490

Short communication

\title{
The Influence of Potential Sweep Cycle Number on the Electrocatalytic Activity of the Boiled PdO/Graphene for Ethanol Oxidation Reaction (EOR)
}

\author{
Keqiang Ding , Yuying Chen, Jing Zhao, Yan Zhang, Binjuan Wei \\ College of Chemistry and Materials Science, Hebei Normal University, Shijiazhuang 050024, P.R. \\ China \\ *E-mail: dkeqiang@263.net
}

doi: $10.20964 / 2016.11 .47$

Received: 17 August 2016 / Accepted: 14 September 2016 / Published: 10 October 2016

\begin{abstract}
A suspension solution consisting of $\mathrm{PdO}$ and graphene was boiled at $200{ }^{\circ} \mathrm{C}$ for $2 \mathrm{~h}$, and the filtered and dried samples were denoted as materials of $\mathrm{PdO} / \mathrm{G}$. Subsequently, the obtained samples were immobilized on a glassy carbon (GC) electrode, producing a PdO/G modified GC electrode. Lastly, the prepared electrodes were swept by a potentiostatic method at the scan rate of $10 \mathrm{mV} \mathrm{s}^{-1}$ in a solution having $\mathrm{PdCl}_{2}$ and $\mathrm{Na}_{2} \mathrm{SO}_{4}$ for various cycles (0, 20, 50 and 80 cycles), yielding four kinds of $\mathrm{PdO} / \mathrm{G}$ electrodes, being denoted as potential sweep cycle (PSC)-treated PdO/G electrodes. The morphologies of the scraped samples were mainly characterized by using Transmission electron microscopy (TEM). And the electrocatalytic abilities of the PSC-treated catalysts towards ethanol oxidation reaction (EOR) were basically examined by using cyclic voltammetry (CV) and chronoamperometry (CA). The electrochemical consequences indicated that the catalyst of $\mathrm{PdO} / \mathrm{G}$ treated by 50 cycles (catalyst c) delivered the best electrocatalytic activity among all as-prepared catalysts. The smaller particle size and higher percentage of $\mathrm{Pd}$ were regarded as the main reasons for the excellent electrocatalytic activity of catalyst $\mathbf{c}$ towards EOR as compared to other catalysts. Showing the fact that the potential sweep cycle could be employed as a method to enhance the electrocatalytic activity of $\mathrm{PdO} / \mathrm{G}$ materials was the main contribution of this short communication.
\end{abstract}

Keywords: PdO; graphene; boiling treatment; potential sweep cycle number; ethanol oxidation reaction; electrocatalysis

\section{$\underline{\text { FULL TEXT }}$}

(C) 2016 The Authors. Published by ESG (www.electrochemsci.org). This article is an open access article distributed under the terms and conditions of the Creative Commons Attribution license (http://creativecommons.org/licenses/by/4.0/). 